\title{
ORIGINAL RESEARCH \\ Hemodynamics and Anatomy of Elastase-Induced Rabbit Aneurysm Models: Similarity to Human Cerebral Aneurysms?
}

\begin{abstract}
Z. Zeng BACKGROUND AND PURPOSE: Animal models provide a mechanism for fundamental studies of the D.F. Kallmes M.J. Durka Y. Ding coupling between hemodynamics and pathophysiology in diseases such as saccular aneurysms. In this
reproduce the anatomic and hemodynamic features typical for human intracranial aneurysms.
\end{abstract} D. Lewis

R. Kadirvel A.M. Robertson

MATERIALS AND METHODS: Saccular aneurysms were created in 51 rabbits at the origin of the RCCA.
Twelve weeks' postcreation, the lumen geometry of the aneurysm and surrounding vasculature was
acquired by using 3DRA. Geometric features of these models were measured. Pulsatile 3D CFD
studies were performed with rabbit-specific inlet profiles.

RESULTS: Geometric features, including aneurysm height, width, neck diameter, aspect ratio, and NSI of all 51 rabbit aneurysm models fell within the range reported for human IAs. The distribution and range in values of pressure, WSS, and OSI were also typical for human IAs. A single recirculation region was observed in $33(65 \%)$ of 51 cases, whereas a second transient recirculation zone was observed in $18(35 \%)$ cases. Both of these flow types are commonly observed in human IAs.

CONCLUSIONS: Most hemodynamic and geometric features in a commonly used elastase-induced rabbit saccular aneurysm model are qualitatively and quantitatively similar to those seen in large numbers of human cerebral aneurysms.

\begin{abstract}
ABBREVIATIONS: $\mathrm{AO}=$ aortic arch; $\mathrm{AR}=$ aspect ratio; $\mathrm{BF}=$ bottleneck factor; $\mathrm{CFD}=$ computational fluid dynamics; $D=$ maximum aneurysm diameter; $D / N=$ bottleneck factor; $D_{D P A}=$ hydraulic diameter of the distal parent artery; DPA = distal parent artery; $\mathrm{D}_{\mathrm{PPA}}=$ hydraulic diameter of the proximal parent artery; 3DRA $=3 \mathrm{D}$ rotational angiography; $\mathrm{H}=$ height of the aneurysm; $\mathrm{H} / \mathrm{N}=$ aspect ratio; $\mathrm{IA}=$ intracranial aneurysm; LCCA = left common carotid artery; $\mathrm{N}=$ neck diameter; $\mathrm{NSI}=$ nonsphericity index; OSI = oscillatory shear index; PA = parent artery; PPA = proximal parent artery; RCCA = right common carotid artery; Re = Reynolds number; $\mathrm{S}=$ aneurysm surface area; TAWSS = time-averaged wall shear stress; $\mathrm{V}=$ aneurysm volume; WSS $=$ wall shear stress
\end{abstract}

$\mathbf{T}$ he ability of the arterial wall to respond appropriately to hemodynamic stresses is critical to arterial health. This response takes the form of short-term changes such as vasodilation as well as long-term structural changes. It is commonly accepted that hemodynamics play a role in the initiation and further development of arterial pathologies such as IAs. These IAs are characterized by degeneration of the internal elastic lamina and media, accompanied by local enlargements of the arterial wall, typically into a saccular shape.

Previous investigators have postulated that the manner in which the walls of IAs remodel under the abnormal intrasaccular hemodynamic stresses plays a major role in the stabilization or eventual rupture of the aneurysm. ${ }^{1-6}$ As a result, a

Received May 6, 2010; accepted after revision July 29.

From the Department of Mechanical Engineering and Materials Sciences (Z.Z., M.J.D.), University of Pittsburgh, Pittsburgh, Pennsylvania; Department of Radiology (D.F.K., Y.D., D.L., R.K.), Mayo Clinic College of Medicine, Rochester, Minnesota; and Department of Mechanical Engineering and Materials Sciences, Center for Vascular Remodeling and Regeneration (A.M.R.), University of Pittsburgh, Pittsburgh, Pennsylvania.

This work was supported by the National Institutes of Health (grant NS42646-02).

Please address correspondence to Anne M. Robertson, PhD, Department of Mechanical Engineering and Materials Science Center for Vascular Remodeling and Regeneration, University of Pittsburgh, 3700 0'Hara St, Pittsburgh, PA 15261; e-mail: rbertson@pitt.edu

Indicates open access to non-subscribers at www.ajnr.org

DOI 10.3174/ajnr.A2324 large body of research has been directed at categorizing the hemodynamics inside human IAs and correlating aneurysm growth as well as rupture with specific hemodynamic markers such as abnormally high or low magnitudes of WSS and OSI. ${ }^{2-8}$ The intra-aneurysmal flow is affected by the geometry of the aneurysm sac and surrounding vasculature; including the existence, size, and symmetry of branches arising near the aneurysm; and the position of the aneurysm sac relative to the parent vessel (eg, sidewall, terminal, or bifurcation). Effort has been made to correlate rupture with these various geometric features. $^{3,9-15}$

The coupling between hemodynamics and aneurysm pathophysiology is complex and remains poorly understood. Patient-specific prognostication regarding risk of rupture might be substantially advanced by improving our understanding of the in vivo response of the aneurysm wall to intrasaccular hemodynamic stresses. ${ }^{16}$ While in vitro systems such as parallel plate and T-chamber flow systems provide an opportunity for highly controlled investigations of cellular response to various types of hemodynamic stresses, such model systems are limited to short-duration studies. ${ }^{17}$ Furthermore, those systems typically only provide information about an isolated layer of endothelial cells, though recent coculture models have yielded results for the coupled response of multiple wall components. ${ }^{18}$ In contrast, animal models provide a mecha- 

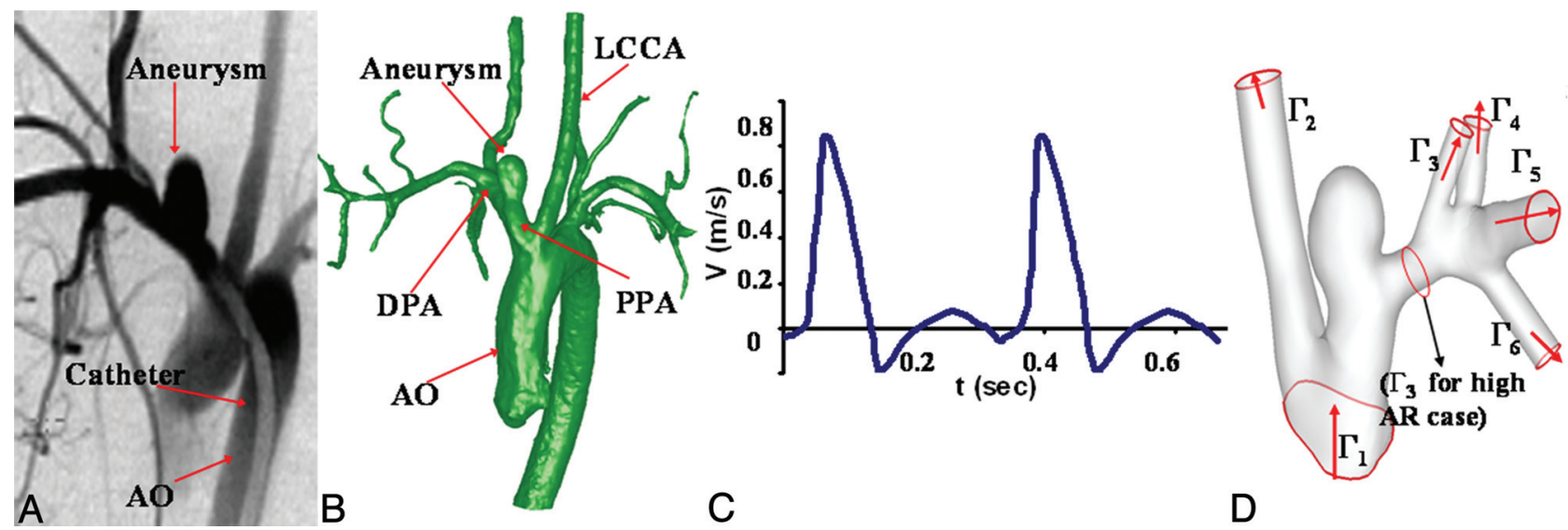

Fig 1. A, Digital subtraction angiogram of an elastase-induced aneurysm. $B$, Reconstructed $3 D$ geometry from 3DRA images. $C$, Idealized maximum velocity waveform applied at inlet. $D$, Computational domain for CFD analysis with flow directions (red arrows), inlet surfaces $\left(\Gamma_{1}\right)$, and outflow surface $\left(\Gamma_{2}\right.$ and $\Gamma_{3}$ for high AR models and $\Gamma_{2}-\Gamma_{6}$ for low AR models).

nism for fundamental studies of the impact of chronically altered WSS on the intact vascular wall. To make meaningful use of these models, one must evaluate their relevance to human biomechanics and pathophysiology.

A number of animal models have been created for studying aneurysm pathogenesis. ${ }^{19-22}$ One such model is a saccular aneurysm model in rabbits in which aneurysms are created by elastase infusion in the RCCA. ${ }^{19}$ This model has previously been used to study the pathobiology of aneurysms and to speed development of numerous endovascular devices. ${ }^{23,24}$ The central goal of the current work is to evaluate the homology of both the geometric and estimated hemodynamic features in elastase-induced rabbit aneurysms compared with previously reported values for human IAs. This comparison is necessary to justify the use of the animal model as a test bed for hemodynamic-based human IA research. Furthermore, the results of this study will enhance our ability to interpret fundamental biologic studies in this model aneurysm system.

To achieve this objective, we evaluated the anatomy and hemodynamics for elastase-induced rabbit aneurysms $(N=$ 51) by using CFD and compared them with published results for human aneurysms. The relevance of this model was evaluated in 2 contexts: The first was to determine whether the range of geometric and hemodynamic parameters of the rabbit model is realistic for humans - that is, do they lie within the range reported for human IAs? The second focus was to determine whether the range of geometric parameters produced in the rabbit model provide a large enough spectrum to test the current hypotheses about the role of geometry in aneurysm development and rupture.

\section{Materials and Methods}

\section{Aneurysm Creation}

Saccular aneurysms were created in 51 New Zealand white rabbits (body weight, 3-4 kg) by using a previously reported protocol ${ }^{19,25-27}$ that was approved by the animal review committee at the Mayo Clinic, Rochester, Minnesota. Briefly, anesthesia was induced with an intramuscular injection of ketamine, xylazine, and acepromazine $(75,5$, and $1 \mathrm{mg} / \mathrm{kg}$, respectively). By using a balloon catheter, we incubated porcine elastase (Worthington Biochemical, Freehold, New Jersey) within the lumen of the proximal RCCA for 20 minutes, after which the balloon was deflated, followed by removal of the catheter system. The RCCA was then ligated at its midportion. Dilated arterial segments were thus formed from the stump of the RCCA, which was defined as an "aneurysm" (Fig $1 A$ ). ${ }^{25}$ For the current study, a range of aneurysm sizes was purposefully created by using previously reported techniques. ${ }^{25-27}$

\section{Imaging Procedures, Lumen Reconstruction, and Arterial Waveforms}

Standard digital subtraction angiography and 3DRA were performed 12 weeks after aneurysm creation using Axiom Artis Zee with Syngo InSpace 3D software (Siemens, Erlangen, Germany). The 3D geometric models of the aneurysm and sections of local vasculature were reconstructed from the serial image data by using Mimics software (Materialise, Leuven, Belgium) (Fig 1B). Arterial waveforms were captured in the LCCA and DPA of each rabbit by using transthoracic duplex Doppler sonography (Acuson Sequoia 512 with a 15L8 transducer, Siemens) (Fig 1C).

\section{Geometric Data Acquisition}

Geometric measurements were obtained from the 3D reconstructed models by using Mimics, Geomagic studio (Geomagic, Research Triangle Park, North Carolina), and SolidWorks (Dassault Systèmes SolidWorks, Concord, Massachusetts). Briefly, the centerlines of the parent vessel and aneurysm were determined, after which the neck cross-section and cross-section of maximum area were extracted perpendicular to the centerline.

The hydraulic neck diameter $(\mathrm{N})$ and maximum aneurysm diameter (D) were measured for these cross-sections. The height of the aneurysm $(\mathrm{H})$ was specified as the distance from the geometric center of the neck cross-section to the aneurysm apex. The aneurysm surface area (S) and aneurysm volume (V) were obtained from numeric integration of the surface and volume of the reconstructed aneurysm sac. The $\mathrm{D}_{\mathrm{PPA}}$ and $\mathrm{D}_{\mathrm{DPA}}$ were measured 1 neck diameter upstream and downstream to the closest edge of the aneurysm neck respectively. We considered 4 nondimensional geometric parameters: the $\mathrm{AR},{ }^{11,28} \mathrm{D} / \mathrm{H},{ }^{9}$ bottleneck factor $(\mathrm{BF}),{ }^{29}$ and nonsphericity index. ${ }^{10}$

$$
\mathrm{AR}=\mathrm{H} / \mathrm{N}, \mathrm{BF}=\mathrm{D} / \mathrm{N}, \mathrm{NSI}=1-(18 \pi)^{1 / 3}(\mathrm{~V})^{2 / 3} / \mathrm{S} .
$$

A cutoff AR of 1.8 was used to distinguish low and high AR aneurysms. This cutoff is intermediate between the value of 1.6 proposed by Ujiie et al $(2001)^{11}$ and Weir et al $(2003)^{12}$ and of 1.85 proposed by Raghavan et al $(2005)^{10}$ as being valuable for predicting IA rupture. 


\begin{tabular}{|c|c|c|c|}
\hline & $\begin{array}{l}\text { Human Aneurysm } \\
\text { Study Compared }\end{array}$ & No. of Aneurysms & $\begin{array}{c}\text { Parameters Reported Corresponding } \\
\text { to Rabbit Aneurysms }\end{array}$ \\
\hline Geometry & $\begin{array}{l}\text { Parlea et al }(1999)^{9} \\
\text { Raghavan et al }(2005)^{10} \\
\text { Jou et al }(2008)^{4}\end{array}$ & $\begin{array}{l}87 \text { Cases } \\
27 \text { Cases: } 9 \text { ruptured; } 18 \text { unruptured } \\
26 \text { Cases: } 8 \text { ruptured; } 18 \text { unruptured }\end{array}$ & $\begin{array}{l}D, H, N, D / h, A R, B F \\
D, H, N, V, S, A R, B F, N S I \\
D_{P A}, N, A R, S\end{array}$ \\
\hline Hemodynamics & $\begin{array}{l}\text { Cebral et al }(2005)^{2} \\
\text { Hassan et al }(2005)^{3} \\
\text { Jou et al }(2008)^{4} \\
\text { Karmonik et al }(2010)^{8} \\
\text { Sirenman et al }(2003)^{7} \\
\text { Shojima et al }(2004)^{5} \\
\text { Shojima et al }(2005)^{6}\end{array}$ & $\begin{array}{l}62 \text { Cases } \\
68 \text { Cases } \\
26 \text { Cases } \\
6 \text { Cases } \\
2 \text { Cases } \\
20 \text { Cases } \\
29 \text { Cases }\end{array}$ & $\begin{array}{l}\text { TAWSS, flow structure, impingement region, pressure, OSI } \\
\text { WSS, flow structure } \\
\text { WSS (end diastole) } \\
\text { OSI } \\
\text { TAWSS, velocity field, flow structure, OSI } \\
\text { WSS (peak systole) } \\
\text { Pressure }\end{array}$ \\
\hline
\end{tabular}

\section{CFD Analysis}

Blood flow in the reconstructed models was simulated on the basis of the unsteady 3D Navier-Stokes equations, by using the finite-element method with ADINA software (64 bit) (Adina R \& D, Watertown, Massachusetts). The blood density and viscosity were chosen as $\rho=$ $1050 \mathrm{~kg} / \mathrm{m}^{3}$ and $\mu=0.0035 \mathrm{~Pa} / \mathrm{s}$, respectively. The extent of the vascular domain necessary to obtain reliable CFD results in the elastaseinduced rabbit model was evaluated in an earlier work. ${ }^{30}$ Following that work, the LCCA, $\mathrm{P}_{\mathrm{PA}}$, DPA and the aneurysm itself were included in the computational domain of the high AR cases. The low AR domains consisted of the high AR domain plus the downstream trifurcation/quadrification structure (Fig 1D).

The vessel wall was idealized as rigid, and the no-slip boundary condition was applied to the walls of all models. The inflow and outflow conditions follow those specified previously. ${ }^{30}$ Briefly, a timevarying uniform velocity profile was specified at all outlets of the models (cross-sections, $\Gamma_{2}-\Gamma_{6}$ for low AR models; $\Gamma_{2}$ and $\Gamma_{3}$, for high AR models) (Fig 1D). The magnitude was chosen to match the animal-specific waveform measured in vivo, as noted above. A modified traction condition or so-called "do nothing" boundary condition was applied at the inlet $\left(\Gamma_{1}\right)$ of all the models. ${ }^{31}$

The finite-element mesh of the computational domain was composed of 40,000-60,000 hexahedral (brick) elements. This mesh attenuation was found to give $<3 \%$ change in maximum WSS compared with results from a model with double the mesh attenuation along the centerline. CFD analyses were performed for each model for a duration of 2 cardiac cycles by using 100 time-steps per cycle. Simulations were performed by using a $3 \mathrm{GHz}$ dual Xeon processor workstation with $8 \mathrm{~GB}$ of memory. The simulation time ranged from 16 to 20 hours, depending on the model size.

\section{Hemodynamic Parameters}

We evaluated several measures of the hemodynamic wall sheer stress vector $\underline{\tau}_{w}$ : the magnitude of the WSS vector, the TAWSS, and the OSI, ${ }^{32}$ defined as,

$$
\begin{gathered}
W S S=\left|\underline{\tau}_{w}\right|, \quad \text { TAWSS }=\frac{1}{T} \int_{0}^{\mathrm{T}}\left|\underline{\tau}_{w}\right| d t, \\
\text { OSI }=\frac{1}{2}\left(1-\frac{\left|\int_{0}^{\mathrm{T}} \underline{\tau}_{\mathrm{w}} \mathrm{dt}\right|}{\int_{0}^{\mathrm{T}}\left|\underline{\tau}_{\mathrm{w}}\right| \mathrm{dt}}\right),
\end{gathered}
$$

where $T$ is the duration of 1 cardiac cycle.
Two dimensionless flow parameters, time-averaged Re and the Womersley number $\alpha$, were also considered.

$$
R e=\frac{\rho U D_{P P A}}{\mu}, \quad \alpha=\frac{D_{P P A}}{2} \sqrt{\frac{2 \pi \rho f}{\mu}},
$$

where $U$ is a cross-sectional average velocity, further averaged over 1 cardiac cycle, and $f$ is the fundamental frequency of the pulsatile waveform.

\section{Human Intracranial Aneurysm Data: Literature Review}

A systematic search of previously published human IA geometric and hemodynamic parameters was conducted by using the following keywords: "cerebral," "aneurysm," "geometry," and "hemodynamics" in the PubMed on-line data base. In general, only studies with at least 20 cases and a quantitative analysis of aneurysm geometry and/or hemodynamics were included in the analysis (Table 1). Only 2 studies were available for quantitative OSI values and distribution in human IAs. ${ }^{7,8}$ Therefore, despite the small sample sizes of 2 and 6 , they were included in the analysis.

\section{Results}

\section{Aneurysm Geometry}

Table 2 and Fig 2 display geometric results for 51 elastaseinduced aneurysm models and human IAs from the literature. Parlea et $\mathrm{al}^{9}$ analyzed the geometry of 87 simple-lobed aneurysms by using $2 \mathrm{D}$ angiographic data. Raghavan et $\mathrm{al}^{10}$ evaluated geometric features from $3 \mathrm{D}$ reconstructions from 27 aneurysms. The dimensional geometric parameters of the 51 cases for the rabbit model all fell within the range reported for human IAs, including aneurysm height, width, neck, volume, and surface area (Table 2, Fig 2A).

The ARs in the 51 prospectively created rabbit aneurysms ranged from 0.56 to 3.98 , with a good distribution of ARs across the cases (Fig 2C). The rabbit AR values fell nearly completely within the range reported for human IAs and were almost evenly split between low and high aneurysms (25 low and 26 high).

The NSI value in the rabbit models ranged from 0.15 to 0.36 , extending above the 0.32 maximum reported in humans (Fig 2B, $D)$. Mean NSI values of 0.156 and 0.233 were reported for unruptured and ruptured human IAs, respectively (Table 2). The range of NSI in the rabbit model includes both these values, though it is skewed toward the higher NSI range (Fig 2B).

The range of rabbit $\mathrm{D} / \mathrm{H}$ values shows excellent agreement with human data, nearly coinciding with the human IA range 
Table 2: Comparison of geometric features in rabbit aneurysms $(N=51)$ and human aneurysms

\begin{tabular}{|c|c|c|c|c|}
\hline \multirow{2}{*}{$\begin{array}{l}\text { Geometric } \\
\text { Features }\end{array}$} & \multicolumn{2}{|c|}{ Rabbit Aneurysms } & \multicolumn{2}{|l|}{ Human Aneurysms $^{\mathrm{a}}$} \\
\hline & Mean & Range & Mean & Range \\
\hline$\overline{D(m m)}$ & $5.27 \pm 1.02$ & $2.46-7.86$ & Ruptured $4.87 \pm 1.86 ;$ unruptured $4.81 \pm 1.37^{10}$ & $1-11.4^{9}$ \\
\hline$N(\mathrm{~mm})$ & $4.12 \pm 1.01$ & $2.35-7.08$ & $\begin{array}{l}\text { Ruptured } 3.79 \pm 1.58 ; \text { unruptured } 4.25 \pm 1.38^{10} \\
\quad \text { ruptured } 4.1 \pm 1.1 ; \text { unruptured } 4.1 \pm 1.2^{4}\end{array}$ & $1.1-12.9^{9}$ \\
\hline$H(\mathrm{~mm})$ & $7.98 \pm 2.79$ & $2.50-14.10$ & Ruptured $6.55 \pm 3.80 ;$ unruptured $5.13 \pm 1.54^{10}$ & $1.5-22.6^{9}$ \\
\hline$D_{P P A}(m m)$ & $4.01 \pm 0.55$ & $3.10-5.25$ & Internal carotid: $3.56 \mathrm{~mm}$; basilar: $3.23 \mathrm{~mm}^{9}$; internal & - \\
\hline $\mathrm{D}_{\mathrm{DPA}}(\mathrm{mm})$ & $3.26 \pm 0.51$ & $2.5-4.23$ & carotid: $4.7 \mathrm{~mm}^{4}$ & \\
\hline$V\left(\mathrm{~mm}^{3}\right)$ & $146 \pm 98$ & $18-478$ & Ruptured $146 \pm 219 ;$ unruptured $84 \pm 59^{10}$ & $13-700^{10}$ \\
\hline$S\left(\mathrm{~mm}^{2}\right)$ & $142 \pm 66$ & 40-331 & $\begin{array}{l}\text { Ruptured } 122 \pm 128 ; \text { unruptured } 83 \pm 41^{10} ; \text { ruptured } \\
\quad 256 \pm 351 ; \text { unruptured } 124 \pm 110^{4}\end{array}$ & $26-442^{10}$ \\
\hline $\mathrm{BF}(\mathrm{D} / \mathrm{N})$ & $1.31 \pm 0.24$ & $1.00-1.91$ & $\begin{array}{l}\text { Ruptured } 1.387 \pm 0.492 ; \text { unruptured } 1.156 \pm 0.171^{10} \\
\quad 1.91 \pm 0.86^{9}\end{array}$ & $0.79-6.35^{9}$ \\
\hline $\mathrm{D} / \mathrm{h}$ & $0.72 \pm 0.25$ & $0.41-1.78$ & $1.11 \pm 0.29^{9}$ & $0.49-1.80^{9}$ \\
\hline$A R(H / N)$ & $2.01 \pm 0.76$ & $0.56-3.98$ & $\begin{array}{l}\text { Ruptured } 1.85 \pm 0.79 ; \text { unruptured } 1.27 \pm 0.40^{10} \\
1.86 \pm 0.86^{9} ; \text { ruptured } 2.0 \pm 0.9 \text {; unruptured } \\
1.5 \pm 0.8^{4}\end{array}$ & $0.60-5.53^{9}$ \\
\hline NSI & $0.28 \pm 0.03$ & $0.15-0.36$ & Ruptured $0.233 \pm 0.061 ;$ unruptured $0.156 \pm 0.058^{10}$ & $0.073-0.32^{10}$ \\
\hline
\end{tabular}

a From published results.
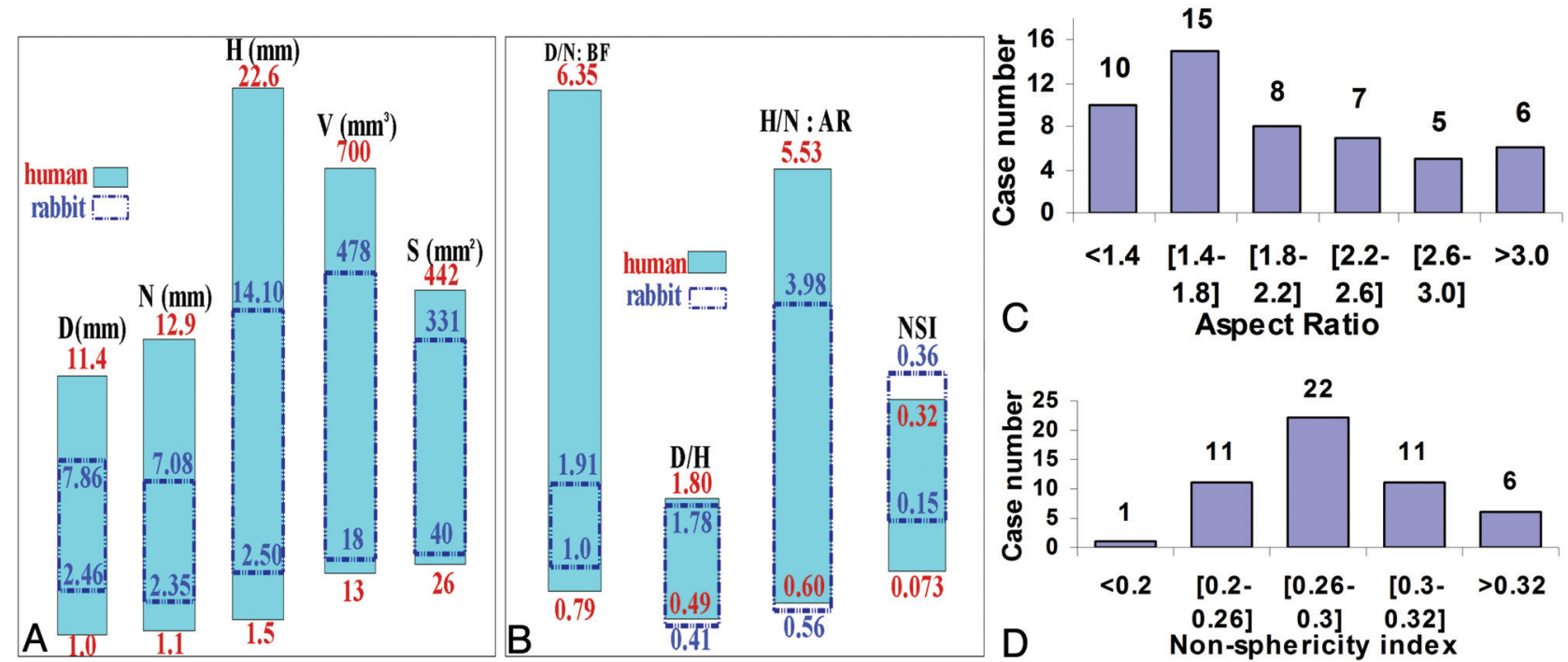

Fig 2. $A$, Range in geometric features for human aneurysms and rabbit model aneurysms: maximum diameter (millimeters), neck diameter (millimeters), height (millimeters), volume (cubic millimeters), and surface area (square millimeters). $B$, Range in geometric indices: $\mathrm{D} / \mathrm{N}, \mathrm{D} / \mathrm{H}, \mathrm{H} / \mathrm{N}$, and NSI. C, Distribution of AR for rabbit aneurysms. $D$, Distribution of NSI for rabbit aneurysms.

(Table 2 and Fig 2B). The rabbit BF values also fall within the human range, though they are at the low end of these values.

\section{Intrasacular Hemodynamics}

Hemodynamic results for all 51 rabbit models are shown in Table 3 and Fig 3. Corresponding results for human IAs are summarized in Table 3.

\section{Nondimensional Flow Parameters}

Re for the rabbit model ranges from 200 to 400, comparing well with values of 200-500 in and around the circle of Willis of humans. ${ }^{33,34}$ The rabbit Womersley number by using a representative $f$ of $3.3 \mathrm{~Hz}$ was 2.5-5.0 compared with reported values of $1.5-5^{35}$ for humans.

\section{Qualitative Features of Flow}

The systolic streamlines for 2 representative rabbit sacs are shown in Fig $3 A$. For all rabbit models, the fluid entered the sac from the distal side and exited from the proximal side. The flow structures could be categorized as type A with a single and stationary circulation inside the aneurysm sac and type B with a transient secondary circulation in the dome as well as a primary (larger) stationary circulation below this. This transient secondary circulation was apparent at diastole and disappeared by systole. For type A flows, the inflow velocity was faster and occupied a smaller percentage of the neck.

In their study of hemodynamics in 62 human IAs, Cebral et $\mathrm{al}^{2}$ identified 4 categories of flow based on the nature of the inflow jet and the number and transient nature of circulation regions in the sac. Type I displayed an inflow jet with an unchanging direction and a single circulation region (44\%) as seen in the type A rabbit model described above. Type III displayed a shifting inflow jet with 1 stationary and 1 transient circulation region (17\%), similar to the type B rabbit model. The other categories observed by Cebral et al displayed multiple stationary circulation patterns (19\%), and 1 stable and 


\begin{tabular}{|c|c|c|}
\hline Hemodynamic Features & Rabbit Aneurysms & Human Aneurysms $^{a}$ \\
\hline Re & Range, 200-400 & Range, $200-500^{33,34}$ \\
\hline$\alpha$ & Range, 2.5-5.0 & Range, $1.5-5.0^{35}$ \\
\hline Flow pattern & $\begin{array}{l}\text { Type A: single stationary recirculation; type B: } \\
\text { single stationary recirculation in lower sac } \\
\text { and secondary transient recirculation in the } \\
\text { dome }\end{array}$ & 4 Flow categories including types $A$ and $B^{2}$ \\
\hline $\begin{array}{l}\text { Pressure difference between parent artery and } \\
\text { sac }(\mathrm{mm} \mathrm{Hg})\end{array}$ & $0.36 \pm 0.19 ;$ Range, $0.1-0.5$ & $0.89 \pm 0.68^{6} ; \sim 0.5^{2}$ \\
\hline OSI & $\begin{array}{l}\text { Elevated } 0.3-0.4 \text { at neck }(N=51) \text {, sidewalls } \\
\quad \text { of sac }(n=15) \text {, dome }(n=18)\end{array}$ & Elevated OSI, 0.24-0.47 at neck, sidewall, and dome $\mathrm{e}^{7,8}$ \\
\hline $\begin{array}{l}\text { Spatially averaged WSS at peak systole } \\
\text { (aneurysm sac, Pa) }\end{array}$ & $0.49 \pm 0.62 ;$ Range, $0.02-3.2$ & $1.64 \pm 1.16^{5} ;$ Range, $0.1-3.4^{5}$ \\
\hline Spatially averaged TAWSS (aneurysm sac, Pa) & $0.13 \pm 0.20 ;$ Range, $0.002-1.23$ & - \\
\hline Spatially averaged WSS at peak systole $\left(\mathrm{P}_{\mathrm{PA}}, \mathrm{Pa}\right)$ & $2.16 \pm 0.93 ;$ Range, $1.02-4.89$ & $3.64 \pm 1.25^{5}$ \\
\hline Spatially averaged TAWSS ( $\left.\mathrm{P}_{\mathrm{PA}}, \mathrm{Pa}\right)$ & $0.81 \pm 0.33 ;$ Range; $0.23-1.48$ & - \\
\hline Location of maximum WSS & Distal neck $(n=51)$ & Neck $^{3,5}$; often at distal neck ${ }^{4}$ \\
\hline Location of minimum WSS & Dome $(<0.1 \mathrm{~Pa})$ & Dome $^{3-5}$ \\
\hline
\end{tabular}

${ }^{a}$ From published results.

multiple transient recirculation regions (20\%). Hence, the flow types in the elastase-induced aneurysms correspond to $61 \%$ of those analyzed by Cebral et al.

The impingement region of the rabbit models is always located at the distal neck, and a slow jet flow is observed at the distal wall. This impingement location was reported in $20 \%$ of all human IAs by Cebral et $\mathrm{al}^{2}$ though impingement was also found at the aneurysm dome and sidewalls.

\section{Wall Pressure}

The spatial variations in pressure within and around the aneurysm sac are small (Fig $3 B$ ). The range in pressure was $<0.05$ $\mathrm{mm} \mathrm{Hg}$ within the sac and $<0.5 \mathrm{~mm} \mathrm{Hg}$ between the sac and its parent artery (Table 3 ). Similarly, the pressure in human IAs is relatively constant and deviates $<1 \mathrm{~mm} \mathrm{Hg}$ from the pressure in the parent vessel (Table 3 ). ${ }^{2,6}$

\section{OSI}

OSI ranged from 0.3 to 0.4 in subregions of the neck of the 51 rabbit aneurysms (Table 3 and Fig 3B). A second region of elevated OSI was found at the top of the aneurysm for all type B flows $(n=18)$ and was not seen in any type A flows. This is to be expected from the transient secondary circulation in those flows. The OSI was also elevated along the sidewalls of the sac for a smaller group of cases $(n=15)$. Literature on human aneurysms similarly reported elevated OSI in the neck, sidewall, and dome. ${ }^{7,8}$ The maximum values of OSI ranged from 0.3 to 0.4 for both human and rabbit aneurysms.

\section{WSS}

The average TAWSS across the PPA of the rabbit models was $0.81 \mathrm{PA}$ and ranged from 0.23 to $1.48 \mathrm{PA}$. TAWSS was markedly lower inside most of the sac and was elevated on the distal neck compared with the parent artery $(n=51)$ (Fig 3C). On the distal neck, the TAWSS was $>0.5 \mathrm{PA}$, while in the aneurysm domes, the TAWSS was $<0.1 \mathrm{PA}$ and nearly uniform $(n=47)$ (Fig 3 and Table 3$)$. While there were large quantitative differences between WSS at peak systole and TAWSS, the qualitative structure was very similar (Fig 3C).

In human aneurysms, the distal neck has been identified as the region of highest WSS. ${ }^{3-5,7}$ Shojima et $\mathrm{al}^{5}$ noted that 18 of 20 middle cerebral artery aneurysms displayed a highly localized region of elevated WSS, either just inside $(n=10)$ or just outside $(n=8)$ the neck. In all 51 rabbit aneurysms, the highest WSS was found at the neck. The WSS inside the rabbit aneurysms was markedly lower $(<1 \mathrm{PA})$ than the WSS in the parent arteries, particularly in the aneurysm dome where it was always $<0.1 \mathrm{PA}$. In contrast, Cebral et $\mathrm{al}^{2}$ reported a second region of highly elevated WSS (on the order of $5 \mathrm{~Pa}$ ) within the upper sac.

\section{Discussion}

The primary focus of this work was to determine whether the geometric and hemodynamic environments created in an elastase-induced aneurysm model in rabbits are similar to those reported for human IAs. This aneurysm model is receiving increased attention as a system for testing novel therapies and for studying fundamental issues in the aneurysm pathophysiology. It is therefore of great importance to demonstrate the relevance of this model to human aneurysms. The results of the current work also provide a data base of geometric and flow properties in a large set $(n=51)$ of elastase-induced aneurysms. Data of this kind will be useful in applications such as the design of representative in vitro systems to complement in vivo studies in the rabbit model.

The dimensional geometric parameters of the 51 elastaseinduced aneurysms all fall in the human range. With the exception of NSI, the nondimensional geometric parameters are nearly within the human IA range.

The AR has been proposed as an important parameter for predicting the likelihood of IA rupture. ${ }^{11,12}$ Recently, methodologies have been developed for constructing a large range of necks and heights in the rabbit model. ${ }^{26,27}$ Using these techniques, we created a good distribution of human AR, evenly divided between low and high ARs. The AR values for the rabbit model lie almost completely within the human range (Fig $2 B$ ).

The recently introduced NSI was found to be the best geometric predictor of rupture in a study of 27 IA considering 13 geometric parameters. ${ }^{10}$ The range of the NSI in the rabbit model includes the mean value reported for both ruptured 

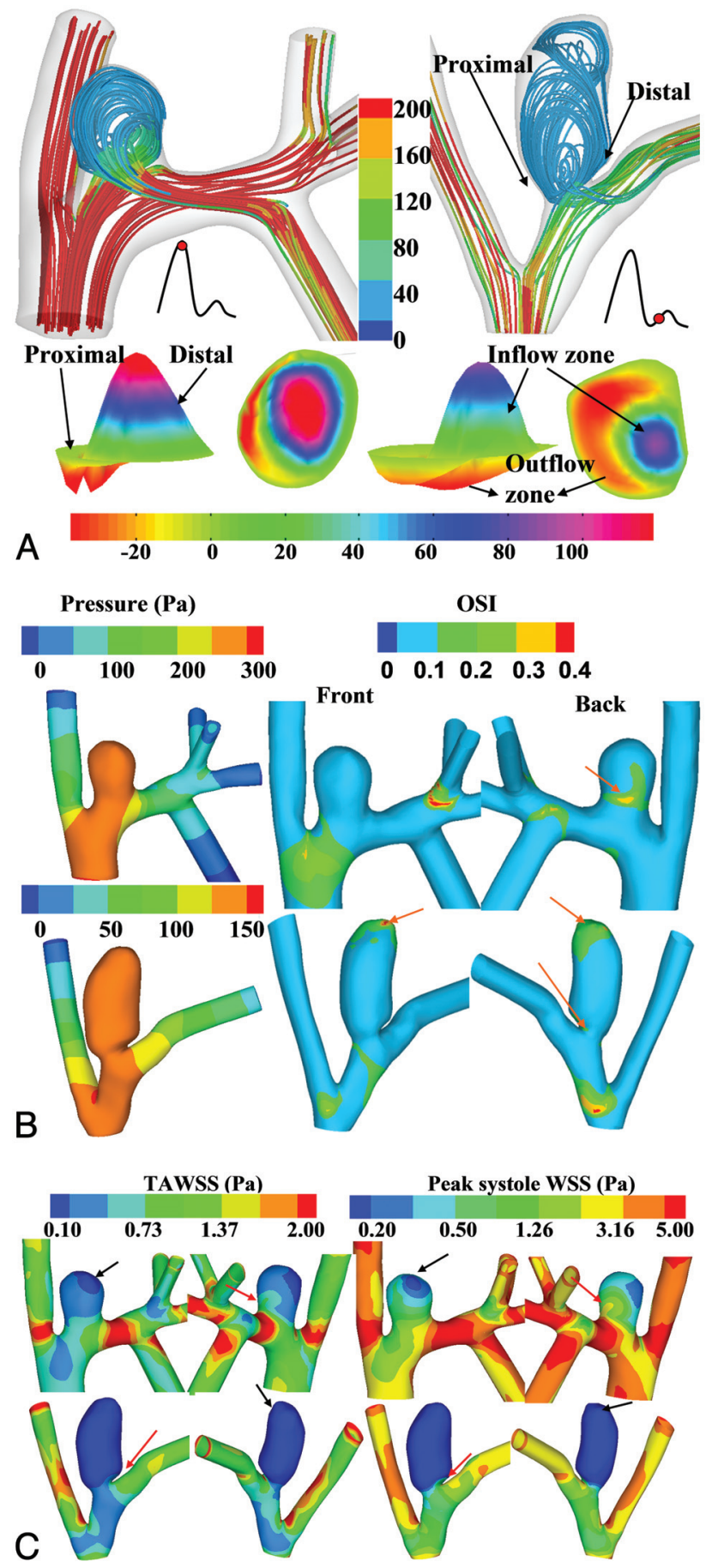

Fig 3. Hemodynamic results for representative low and high AR cases. A, Top row: Streamlines at peak systole displaying 2 types of flow structures. Color designates velocity magnitude (millimeters per second). Bottom row: Corresponding normal component of velocity (millimeters per second) at the aneurysm neck are shown below. Heights are not drawn to scale. Color reflects magnitude. $B$, Left column: Pressure (left column, pascals) at peak systole relative to zero reference pressure at the inlet surface $\Gamma_{1}(1 \mathrm{~mm} \mathrm{Hg}=133.3$ Pa). Center and right columns: Two views of OSI distribution. Arrows indicate regions of elevated OSI. C, TAWSS (pascals) and WSS (pascals) at peak systole (1 PA $=10$ dynes $/ \mathrm{cm}^{2}$ ). WSS contours in logarithmic scale. Red and black arrows indicate the maximum/minimum value in aneurysm sac.

and unruptured human IAs, though it is skewed toward the higher NSI range (Fig 2B). If the clinical usefulness of this shape index is supported by a larger prospective study, it may be worthwhile to increase the pool of low NSI cases in future rabbit studies. This shape ratio does not distinguish between increases in surface area from different causes such as ellipticity and surface undulation, and it does not distinguish between different orientations of the long axis of the aneurysm relative to the parent vessel.

No data are available for the correlation of $\mathrm{D} / \mathrm{H}$ and IA rupture. However, both the $\mathrm{BF}$ and the geometric ratio $\mathrm{D} / \mathrm{H}$ have been proposed as useful parameters for predicting the success of endovascular coil placement and surgical clip applications. ${ }^{29}$ The range of rabbit $\mathrm{D} / \mathrm{H}$ values nearly coincides with human values. While the range of BF in the rabbit model is in the low range for human IAs, it includes the mean for both ruptured and unruptured IAs (Table 2 and Fig $2 B$ ). ${ }^{10}$

Cebral et $\mathrm{al}^{2}$ categorized the human intra-aneurysmal flow into 4 types depending on the complexity and transient nature of the flow: Types I and III were identified in 50\% and 79\% of human bifurcation and terminal aneurysms, respectively. These same 2 flow types are the most common in the rabbit model, despite the fact that it is more similar to a sidewall aneurysm. This is likely due to the influence of the surrounding vasculature. The rabbit aneurysm is just downstream of a large branch (LCCA) and lies on a curve segment of the artery. Curvature has been shown to affect flow in sidewall aneurysms in human models. ${ }^{36,37}$

The spatial distribution of WSS and OSI in and around the rabbit aneurysm sac is typical for large groups of human IAs. ${ }^{2-5,7,8}$ The ranges in Re and $\alpha$ for the 51 rabbits are also in very good agreement with typical values for humans. However, $\alpha$ includes information about the frequency of the waveform but not its shape or magnitude. The rabbit aneurysms are constructed along extracranial vessels and exposed to low or absent antegrade flow during diastole, in contrast to human intracranial vessels, which are exposed to constant antegrade flow. ${ }^{38}$ This difference is likely responsible for the diminished WSS maximum and flow rates found in the rabbit model compared with some human aneurysms. The relatively constant pressure distribution and small deviation from parent vessel pressure inside the aneurysm sac of the rabbit model are also observed in human cerebral aneurysms. ${ }^{2,6}$ This similarity is consistent with the low-inflow speed and slow secondary recirculation in the sac.

This work extends an earlier study of a smaller number of rabbit subjects in which geometric parameters were measured at 2 weeks by using $2 \mathrm{D}$ angiograms and compared with human IAs. ${ }^{39}$ In the present work, a much wider range of geometric parameters was determined from 3D reconstructions of the lumen. Hemodynamic results were previously reported in a smaller study of flow in 5 rabbit aneurysms ${ }^{40}$ and are consistent with those reported here.

This study had a number of limitations. As for most CFD studies of intra-aneurysmal flow, we have assumed that the flow domain is fixed (rigid walls). In both human and rabbit aneurysms, the elastin component is absent or nearly absent, resulting in much stiffer walls than those found in the surrounding arteries. The motion of the aneurysm wall is generally accepted as being of secondary importance compared with geometric and unsteady flow effects. ${ }^{7}$ On the basis of earlier results, ${ }^{30}$ we applied modified traction boundary conditions at the inlet of the computational domain. In the future, we in- 
tend to further evaluate this choice by using phase-contrast MR angiograms in the parent vessels. ${ }^{41}$

The identification of the most significant hemodynamic and geometric parameters for aneurysm growth and rupture remains an active area of research. We have confined attention to parameters that are currently considered significant. In some cases, such as for the OSI and NSI, the data are somewhat sparse and the clinical relevance is still under investigation.

While the flow structures and geometry of the rabbit model successfully reproduce those commonly found in human IAs, including bifurcation and terminal aneurysms, they do not span all types of flow categories identified in humans. Furthermore, it is possible that there is some other important as yet unidentified aspect of flow that is different in bifurcation and terminal aneurysm geometries. It could be of interest in the future to develop animal models with the other 2 flow types identified by Cebral et $\mathrm{al}^{2}{ }^{2}$ as well as bifurcation or terminal aneurysm geometries.

In this work, we have confined attention to a comparison of geometry and hemodynamics. Future investigations will evaluate growth and remodeling in the rabbit model and will compare these results with published data for human aneurysms. The current work lays an important foundation for these studies.

\section{Conclusions}

Hemodynamic and geometric features in a commonly used elastase-induced rabbit saccular aneurysm model are qualitatively and quantitatively similar to those seen in large numbers of human cerebral aneurysms.

\section{References}

1. Burleson AC, Turitto VT. Identification of quantifiable hemodynamic factors in the assessment of cerebral aneurysm behavior: on behalf of the Subcommittee on Biorheology of the Scientific and Standardization Committee of the ISTH. Thromb Haemost 1996;76:118-23

2. Cebral JR, Castro MA, Burgess JE, et al. Characterization of cerebral aneurysms for assessing risk of rupture by using patient-specific computational hemodynamics models. AJNR Am J Neuroradiol 2005;26:2550-59

3. Hassan T, Timofeev EV, Saito T, et al. A proposed parent vessel geometrybased categorization of saccular intracranial aneurysms: computational flow dynamics analysis of the risk factors for lesion rupture. J Neurosurg 2005; 103:662-80

4. Jou LD, Lee DH, Morsi $\mathrm{H}$, et al. Wall shear stress on ruptured and unruptured intracranial aneurysms at the internal carotid artery. AJNR Am J Neuroradiol 2008;29:1761-67

5. Shojima M, Oshima M, Takagi K, et al. Magnitude and role of wall shear stress on cerebral aneurysm: computational fluid dynamic study of 20 middle cerebral artery aneurysms. Stroke 2004;35:2500-05

6. Shojima M, Oshima M, Takagi K, et al. Role of the bloodstream impacting force and the local pressure elevation in the rupture of cerebral aneurysms. Stroke 2005;36:1933-38

7. Steinman DA, Milner JS, Norley CJ, et al. Image-based computational simulation of flow dynamics in a giant intracranial aneurysm. AJNR Am J Neuroradiol 2003;24:559-66

8. Karmonik C, Yen C, Diaz O, et al. Temporal variations of wall shear stress parameters in intracranial aneurysms: importance of patient-specific inflow waveforms for CFD calculations. Acta Neurochir (Wien) 2010;152:1391-98, discussion 1398

9. Parlea L, Fahrig R, Holdsworth DW, et al. An analysis of the geometry of saccular intracranial aneurysms. AJNR Am J Neuroradiol 1999;20:1079-89

10. Raghavan ML, Ma B, Harbaugh RE. Quantified aneurysm shape and rupture risk. J Neurosurg 2005;102:355-62

11. Ujiie $\mathrm{H}$, Tamano $\mathrm{Y}$, Sasaki $\mathrm{K}$, et al. Is the aspect ratio a reliable index for predicting the rupture of a saccular aneurysm? Neurosurgery 2001;48:495-502, discussion 502-03

12. Weir B, Amidei C, Kongable G, et al. The aspect ratio (dome/neck) of ruptured and unruptured aneurysms. J Neurosurg 2003;99:447-51

13. Avolio A, Avolio A, Farnoush A, et al. Hemodynamic models of cerebral aneurysms for assessment of effect of vessel geometry on risk of rupture. Conf Proc IEEE Eng Med Biol Soc 2009;2009:2351-53
14. Piccinelli M, Veneziani A, Steinman DA, et al. A framework for geometric analysis of vascular structures: application to cerebral aneurysms. IEEE Trans Med Imaging 2009;28:1141-55

15. Ingebrigtsen $\mathrm{T}$, Morgan, $\mathrm{MK}$, Faulder $\mathrm{K}$, et al. Bifurcation geometry and the presence of cerebral artery aneurysms. J Neurosurg 2004;101:108-13

16. Frosen J, Piippo A, Paetau A, et al. Remodeling of saccular cerebral artery aneurysm wall is associated with rupture: histological analysis of 24 unruptured and 42 ruptured cases. Stroke 2004;35:2287-93

17. Zeng Z, Chung BJ, Durka M, et al. An in-vitro device for evaluation of cellular response to flows found at the apex of arterial bifurcations. In: A Sequeira A, Rannacher R, eds. Advances in Mathematical Fluid Mechanics. Heidelberg, Germany: Springer-Verlag, Wien; 2010:631-57

18. Sakamoto N, Ohashi T, Sato M. Effect of fluid shear stress on migration of vascular smooth muscle cells in cocultured model. Ann Biomed Eng 2006;34: 408-15. Epub 2006 Feb 16

19. Altes TA, Cloft HJ, Short JG, et al. 1999 ARRS Executive Council Award: creation of saccular aneurysms in the rabbit-a model suitable for testing endovascular devices. American Roentgen Ray Society. AJR Am J Roentgenol 2000;174:349-54

20. Fukuda S, Hashimoto N, Naritomi H, et al. Prevention of rat cerebral aneurysm formation by inhibition of nitric oxide synthase. Circulation 2000;101: 2532-38

21. Kondo S, Hashimoto N, Kikuchi H, et al. Cerebral aneurysms arising at nonbranching sites: an experimental study. Stroke 1997;28:398-403, discussion 403-04

22. Thiex R, Moller-Hartmann W, Hans FJ, et al. Are the configuration and neck morphology of experimental aneurysms predictable? A technical approach. Neuroradiology 2004;46:571-76

23. Kallmes DF, Ding YH, Dai D, et al. A new endoluminal, flow-disrupting device for treatment of saccular aneurysms. Stroke 2007;38:2346-52

24. Sadasivan C, Cesar L, Seong J, et al. An original flow-diversion device for the treatment of intracranial aneurysms: evaluation in the rabbit elastaseinduced model. Stroke 2009;40:952-58

25. Ding YH, Danielson MA, Kadirvel R, et al. Modified technique to create morphologically reproducible elastase-induced aneurysms in rabbits. Neuroradiology 2006;48:528-32

26. Ding YH, Dai D, Lewis DA, et al. Can neck size in elastase-induced aneurysms be controlled? A prospective study. AJNR Am J Neuroradiol 2005;26:2364-67

27. Ding YH, Dai D, Lewis DA, et al. Can neck size in elastase-induced aneurysms be controlled? A retrospective study. AJNR Am J Neuroradiol 2006;27:1681-84

28. Ujiie $H$, Tachibana $H$, Hiramatsu $O$, et al. Effects of size and shape (aspect ratio) on the hemodynamics of saccular aneurysms: a possible index for surgical treatment of intracranial aneurysms. Neurosurgery 1999;45:119-29, discussion 129-30

29. Ebina K, Shimizu T, Sohma M, et al. Clinico-statistical study on morphological risk factors of middle cerebral artery aneurysms. Acta Neurochir (Wien) 1990; 106:153-59

30. Zeng Z, Kallmes DF, Durka M, et al. Sensitivity of CFD based hemodynamic results in rabbit aneurysm models to idealizations in surrounding vasculature. J Biomech Eng 2010;132:091009

31. Heywood JG, Rannacher R, Turek S. Artificial boundaries and flux and pressure conditions for the incompressible Navier-Stokes equations. International Journal for Numerical Methods in Fluids 1996;22:325-52

32. He X, Ku DN. Pulsatile flow in the human left coronary artery bifurcation: average conditions. J Biomech Eng 1996;118:74-82

33. Hendrikse J, van Raamt AF, van der Graaf Y, et al. Distribution of cerebral blood flow in the circle of Willis. Radiology 2005;235:184-89

34. Zhao M, Amin-Hanjani S, Ruland S, et al. Regional cerebral blood flow using quantitative MR angiography. AJNR Am J Neuroradiol 2007;28:1470-73

35. Vriens EM, Wieneke GH, Hillen B, et al. Flow redistribution in the major cerebral arteries after carotid endarterectomy: a study with transcranial Doppler scan. J Vasc Surg 2001;33:139-47

36. Mantha A, Karmonik C, Benndorf G, et al. Hemodynamics in a cerebral artery before and after the formation of an aneurysm. AJNR Am J Neuroradio 2006;27:1113-18

37. Hoi $\mathrm{Y}, \mathrm{Meng}, \mathrm{H}$, Woodward $\mathrm{SH}$, et al. Effects of arterial geometry on aneurysm growth: three-dimensional computational fluid dynamics study. J Neurosurg 2004;101:676-81

38. Yilmaz C, Utebay B, Kalaycioglu S, et al. Non-visualization of the internal carotid artery with a normal ipsilateral common carotid artery Doppler waveform: a finding suggesting congenital absence of the ICA on colour Doppler ultrasound. Br J Radiol 2006;79:108-11

39. Short JG, Fujiwara NH, Marx WF, et al. Elastase-induced saccular aneurysms in rabbits: comparison of geometric features with those of human aneurysms. AJNR Am J Neuroradiol 2001;22:1833-37

40. Kadirvel R, Ding Y-H, Dai D, et al. The influence of hemodynamic forces on biomarkers in the walls of elastase-induced aneurysms in rabbits. Neuroradiology 2007;49:1041-53

41. Karmonik C, Klucznik R, Benndorf G. Blood flow in cerebral aneurysms: comparison of phase contrast magnetic resonance and computational fluid dynamics-preliminary experience. Rofo 2008;180:209-15 